\title{
Active Learning Improves Student Performance in a Respiratory Physiology Lab
}

\author{
Alex M. Wolf ${ }^{1, *}$, Carlos Liachovitzky ${ }^{1} \&$ Abass S. Abdullahi ${ }^{1}$ \\ ${ }^{1}$ Department of Biological Sciences, Bronx Community College, City University of New York, Bronx, New York \\ *Corresponding author: Department of Biological Sciences, Bronx Community College, Bronx, New York 10453. Tel: \\ 1-718-289-5525. E-mail: alexander.wolf@bcc.cuny.edu
}

Received: November 4, 2014

Accepted: November 24, 2014

Online Published: December 10, 2014

doi:10.5430/jct.v4n1p19

URL: http://dx.doi.org/10.5430/jct.v4n1p19

\begin{abstract}
This study assessed the effectiveness of the introduction of active learning exercises into the anatomy and physiology curriculum in a community college setting. Specifically, the incorporation of a spirometry-based respiratory physiology lab resulted in improved student performance in two concepts (respiratory volumes and the hallmarks of respiratory diseases) but not a third (the relationship between volume, pressure and airflow). Anonymous post-lab surveys indicated that the modification increased student's interest in the subject and encouraged interactive learning as well as the use of technology in the classroom. However, although test sections outperformed control sections in the lab midterm, the difference was statistically insignificant, presumably due to the fact that respiratory concepts only accounted for less than $20 \%$ of the exam.
\end{abstract}

Keywords: active learning; spirometry lab; respiratory physiology lab; respiratory volumes; community college

\section{Introduction}

\subsection{Background}

The factors that influence a student's ability to successfully complete the steps leading to an allied health career have been the subject of a great deal of research. Studies have shown that, among other factors, students' age (Beeson \& Kissling, 2001; Yates \& Sandiford, 2013), the number of transfer credits (Simon, McGinniss, \& Krauss, 2013) and performance on standardized tests of nursing content (e.g., adult medical-surgical, pharmacology and maternal-newborn nursing) (Yeom, 2013) are important determinants of student success.

One of the strongest statistical correlates with the successful attainment of nursing credentials is pre-clinical academic performance. Grades in nursing prerequisites such as anatomy and physiology and higher entry GPAs are positively correlated with passing the National Council Licensure Examination for Registered Nurses (NCLEX-RN) (Gilmore, 2008; Quick, Krupa, \& Whitley, 1985; Seldomridge \& DiBartolo, 2004) and performance in nursing courses (Newton, Smith, Moore, \& Magnan, 2007). SAT \& ACT scores (Grossbach \& Kuncel, 2011) are also positively correlated with success on the NCLEX-RN. These studies and others suggest that improving student performance in pre-clinical courses can be determinative for students' successful completion of the steps necessary for a career in allied health.

\subsection{The Benefits of Active Learning}

In these pre-clinical courses, like most courses at most colleges and universities today, the traditional lecture is the pedagogical norm for most students. This is the case, despite the fact that the drawbacks of the traditional lecture have been clear for some time (Dewey \& Dewey, 1915) and abundant research has shown that the lecture is an ineffective way to promote critical thinking (Bligh, 1998).

At the same time that the limitations of the traditional lecture become more apparent, data continue to accrue suggesting the advantages of more hands-on, active approaches to learning. According to Bonwell \& Eison (1991) "in the context of the college classroom, active learning involves students in doing things and thinking about the things they are doing." Active learning is a multifaceted approach to pedagogy. It incorporates multiple concepts such as student-centered learning, collaborative, team-based or small group activities, process-oriented learning, 
discussion groups and problem-based learning (Bonwell \& Eison, 1991; Bransford, Brown, \& Cocking, 2000; Halonen, Brown-Anderson, \& McKeachie, 2002). Research from numerous academic fields has shown that the incorporation of active learning methods improves student learning (Dantas \& Kemm, 2008; Klein \& Doran, 1999; McKeachie \& Svinicki, 2005; J. Michael, 2006; Yoder \& Hochevar, 2005) and the benefits of this approach are substantial, even considering the extra preparation and planning necessary (Sciutto, 1995). The benefits extend to improving class attendance and perceived value of education (McLaughlin et al., 2014). A recent comprehensive meta-analysis of undergraduate STEM education reported significant improvements in student performance on examinations and concept inventories, and on likelihood to achieve a passing grade in active learning sections over traditional sections (Freeman et al., 2014).

\subsection{Active Learning in the Anatomy \& Physiology Laboratory}

In the anatomy and physiology laboratory active learning techniques can be especially effective in improving student learning outcomes (Abraham et al., 2012; Brown, 2010; DiPasquale, Mason, \& Kolkhorst, 2003; Nieder, Parmelee, Stolfi, \& Hudes, 2005; Rathner, Hughes, \& Schuijers, 2013; Vasan, DeFouw, \& Holland, 2008) and in student perception of their learning (Harrison, Nichols, \& Whitmer, 2001; Rodenbaugh, Lujan, \& DiCarlo, 2012). Ultimately, prioritizing problem-based learning, over memorization, will produce better-equipped health care professionals (S. A. Miller, Perrotti, Silverthorn, Dalley, \& Rarey, 2002).

Asking students to investigate the functioning of their own bodies falls into the paradigm of active learning and evidence suggests that the use of student-generated data improves student perception of learning (Stork, 2003) and interest (Somers, Dilendik, \& Smolansky, 1996). Students' motivation to learn concepts in anatomy and physiology is increased when students are allowed to study their own body's processes in a safe environment (McManus \& Sieler, 1998). The use of data acquisition systems is thus an ideal approach to active learning that incorporates student-generated data. These systems take analog input (such as pressure readings from a sphygmomanometer, pulse readings, audible input from a stethoscope, etc.) and convert it to a digital readout. Students see the data being collected in real time and can interact and manipulate their recordings immediately. According to multiple groups, incorporating these systems as part of a transition to active-learning-based laboratory curricula improves learning outcomes and student perceptions of learning (Casotti, Rieser-Danner, \& Knabb, 2008; Chaplin, 2003; Zimmermann $\&$ Eckert, 2010). The real-time nature of the system is beneficial, as delays in producing the graphical output from generated data can inhibit learning of the underlying concept (Brasell, 1987).

\subsection{Study Objectives}

As reported here, we investigated the impact of modifying a respiratory physiology lab to include active learning through the use of student-generated data. Our study had three goals: First, we compared the performance of students in the modified labs with students in previous sections. Second, within sections using the modified lab we compared performance on concepts from the modified lab with concepts from the rest of the semester. Finally, after the completion of the lab we asked students about their perceptions of learning in the modified labs.

\section{Method}

The study was conducted at Bronx Community College, a campus of the City University of New York, over the course of six semesters between 2009 and 2012, comprising 8 sections of a second-semester Anatomy \& Physiology course. This is a 4-credit course, comprising three laboratory hours and three lecture hours per week. The course serves students preparing to enter Allied Health fields, primarily Nursing, but including Radiation Technology, Nutrition, Nuclear Medicine, and others shown in Table 1. The same instructor taught all sections.

Four "control" sections ( $\mathrm{n}=76$ students) were taught using the standard, previously developed curriculum. In these sections the Respiratory Volumes and Function labs consisted primarily of passive pedagogical activities, such as searching for answers to provided lab questions in the textbook. The only participatory activity was an optional exercise to calculate the difference in alveolar ventilation rate before and after activity (running up and down the stairs). Otherwise, students would work with the textbook, often on their own, to find the answers to questions posed in the lab.

Four "test" sections ( $\mathrm{n}=73$ students) were taught using a modified curriculum, designed to incorporate principles of active learning, using student-generated data. In the modified sections the labs took place entirely using a data acquisition device. The device takes analog input from a modified spirometry apparatus and digitizes it for display and analysis. As students inspire and expire a trace appears on the screen, displaying real-time changes in a number of spirometry values. In our lab the device allowed students to generate and examine data for respiratory volumes 
(e.g., tidal volume, inspiratory/expiratory reserve, etc.) as well as pulmonary function (e.g., forced expiratory volume in one second $\left(\mathrm{FEV}_{1}\right)$ and peak inspiratory/expiratory flow)

As Table 1 indicates, the student populations were similar in composition, in terms of percentage of male and female students, declared major and academic progress.

Table 1. Comparison of Student Populations in Control and Test sections

\begin{tabular}{llll}
\hline & & Control $(\mathrm{n}=76)$ & Test $(\mathrm{n}=73)$ \\
\hline Gender & & \\
& Female & $65(85.5 \%)$ & $57(78.1 \%)$ \\
Male & $11(14.5 \%)$ & $16(21.9 \%)$ \\
\hline Major & & $39(53.4 \%)$ \\
& Nursing (AAS) & $36(47.4 \%)$ & $14(19.2 \%)$ \\
& Liberal Arts \& Sciences (AS or AA) & $10(13.2 \%)$ & $9(12.3 \%)$ \\
Dietetics \& Nutrition (AS) & $6(7.9 \%)$ & $1(1.4 \%)$ \\
& Community Schooling/Health Education (AS) & $5(6.6 \%)$ & $3(4.1 \%)$ \\
Radiologic Technology (AAS) & $5(6.6 \%)$ & $7(9.6 \%)$ \\
Class & $14(18.4 \%)$ & $40(54.8 \%)$ \\
& Oreshman & $33(43.4 \%)$ & $29(39.7 \%)$ \\
& Sophomore & $32(42.1 \%)$ & $4(5.5 \%)$ \\
$2^{\text {nd }}$ Degree & $8(10.5 \%)$ & 0 \\
\hline Average on midterm exam $(\mathrm{p}>0.05)$ & No degree & $3(3.9 \%)$ & $74.6 \%$ \\
\hline
\end{tabular}

To test the impact of the modifications we focused on three main concepts in respiratory physiology and identified the lab activities that were designed to illustrate these concepts. As shown in Table 2, there is a significant difference in lab activities between the control and test groups. The control labs are primarily passive, with most activities requiring students to find the answers to questions in the textbook. In the test labs, however, an active component was added. Using the data acquisition device, students first generate data based on their own (or someone in their group's) respiratory physiology and then analyze that data to answer questions posed in the lab.

In the Test section groups of four students were assigned to a station with the data acquisition system. Each person within a group was given a task to promote collaborative learning: The reader kept track of the protocol and directed others, making sure each step in the procedure was followed; the operator interacted with the computer (logged-on, started \& stopped data recording, calibrated equipment, entered subject information, etc.); the housekeeper retrieved the necessary materials from the front of the classroom, kept track of the time and made sure equipment was set up correctly and was functioning properly during the procedure and the subject produced data by breathing in and out of the spirometry equipment.

Table 2. Comparison of Activities in Control and Test Sections

\begin{tabular}{lll}
\hline Concept & Control Sections & Test Sections \\
\hline $\begin{array}{l}\text { Relationship between } \\
\text { lung volume, pressure } \\
\text { and flow }\end{array}$ & $\begin{array}{l}\text { Students are given a sentence and asked to } \\
\text { choose the correct option. (e.g., When the } \\
\text { diaphragm contracts, the volume of the } \\
\text { thoracic cavity (increases/decreases), } \\
\text { pressure (increases/decreases), and air } \\
\text { flows (inward/outward). }\end{array}$ & $\begin{array}{l}\text { As they use spirometry apparatus, students are } \\
\text { prompted to consider the movement of the } \\
\text { diaphragm, whether lungs are expanding or } \\
\text { contracting and the change in volume of the } \\
\text { lungs. Simultaneously students are able to see } \\
\text { the changes in lung volume through a moving } \\
\text { trace on the screen. }\end{array}$ \\
\hline $\begin{array}{ll}\text { Respiratory Volumes } \\
\text { and function }\end{array}$ & $\begin{array}{l}\text { Students are given a static graph and asked } \\
\text { to identify respiratory volumes. They are } \\
\text { also asked to match definitions to the } \\
\text { corresponding volume. }\end{array}$ & $\begin{array}{l}\text { Students perform breathing exercises to } \\
\text { measure tidal volume, inspiratory and } \\
\text { expiratory reserve. Using estimates for } \\
\text { residual volume, other values such as vital } \\
\text { capacity are calculated. Simultaneously } \\
\text { students are able to see the changes in lung } \\
\text { volume through a moving trace on the screen. }\end{array}$ \\
& &
\end{tabular}


Students are asked to define the forced expiratory volume in one second $\left(\mathrm{FEV}_{1}\right)$
Students inspire maximally then expire forcefully and fully. Changes in lung volume through a moving trace on the screen, and on-screen analysis enables students to determine total expiratory volume and the percentage expired after one second.

Activities simulate obstructive and restrictive respiratory diseases. Students can see changes in lung volume through a moving trace on the screen, and see clearly the impact on vital capacity and $\mathrm{FEV}_{1}$.

Table 3. Sample Questions from Midterm Exams

\begin{tabular}{ll}
\hline Concept & Question \\
\hline Volume-Pressure & True or false: During expiration lung volume decreases \\
\cline { 2 - 2 } Relationship & $\begin{array}{l}\text { As the lungs move from position A to B [image showing inspiration] intrapulmonary pressure } \\
\text { (increases/decreases) and air flows (out/in) }\end{array}$ \\
\cline { 2 - 2 } & When the ribs move from position A to B [image showing ribs moving during expiration] the \\
& volume of the thoracic cage (increases/decreases) and the pressure (increases/decreases) \\
\hline Respiratory & [Students are shown a graph of time versus volume] \\
Volumes & Identify the measurement indicated \\
\cline { 2 - 3 } & Which of the following best describes vital capacity? \\
a) The volume of air that can be inspired in addition to tidal volume \\
b) The total volume of air used in gas exchange \\
c) The volume of air that always remains in the lungs \\
d) The "stretchiness" of the lungs
\end{tabular}

Respiratory

Diseases ents are asked to identify the diseas in $\mathrm{FEV}_{1}$ and to explain their answer.

Restrictive pulmonary diseases:

a) Reduce pulmonary compliance

b) Often replace healthy lung tissue with scar tissue

c) Include tuberculosis and black-lung disease

d) All of these things describe restrictive pulmonary disease

You suspect your patient might have an obstructive respiratory disease. Which of the following will confirm your suspicion?

a) Vasodilation of the bronchioles

b) Inflammation of the bronchioles

c) Signs of scarring in the diaphragm

a) Signs of scarring in the lung tissue

In the lab exercise we simulated a bronchial constriction by placing tape over the breathing tube. Which value is most likely to be affected in this simulation? [Used in Test sections only]
a) $\mathrm{FEV}_{1}$
b) Inspiratory Reserve Volume
c) Vital Capacity
d) Residual volume

The effect of the modification on student learning outcomes was measured by examining performance on questions on the midterm examination through questions designed to assess learning of three main concepts in respiratory physiology (Table 2 and see example questions in Table 3 ).

Immediately after completing the lab students were asked to rate their perception of the new lab using a modified version of the Student Assessment of Learning Gains (SALG) survey. The survey avoids critiques of the instructor, the instructor's performance, and teaching methods and instead focuses on student estimates of what they have gained (Seymour, Wiese, Hunter, \& Daffinrud, 2000). As shown in Table 4, students were asked to rank the labs in a number of areas using a Likert scale, including understanding of concepts, interest in the concepts, confidence in the use of technology, and preference. 


\section{Results}

\subsection{Mid-term Performance in Control vs. Test Sections}

On the midterm exam overall, there was a slight, though statistically insignificant, difference between the test and control sections $(74.6 \pm 13.7 \%$ Test vs. $71.8 \pm 13.5 \%$ Control, $p>0.05)$. This result is unsurprising because of the cumulative nature of the exam. We expected that other aspects of the exam, constituting approximately $80 \%$ of the questions, might obscure any change that resulted from the introduction of the active learning labs.

When the performance on the spirometry concepts was isolated and analyzed, a significant difference was seen between the test and control sections (Figure 1). Three types of concept questions were identified. On questions relating to the relationship between pressure, volume and airflow, the test sections $(74.3 \pm 12.5 \%)$ performed better than the control sections $(66.3 \pm 9.6 \%)$, though the difference was not significant $(\mathrm{p}=0.09)$. However, on questions relating to the measurement and identification of respiratory volumes (Test: $77.9 \pm 9.2 \%$, Control: 69.5 $\pm 9.7 \%, \mathrm{p}<0.05$ ) and on the hallmarks of restrictive and obstructive diseases (Test: $77.5 \pm 12.7 \%$, Control: $57.2 \pm 12.2 \%, p<0.005$ ), the test sections performed significantly better than the control sections.

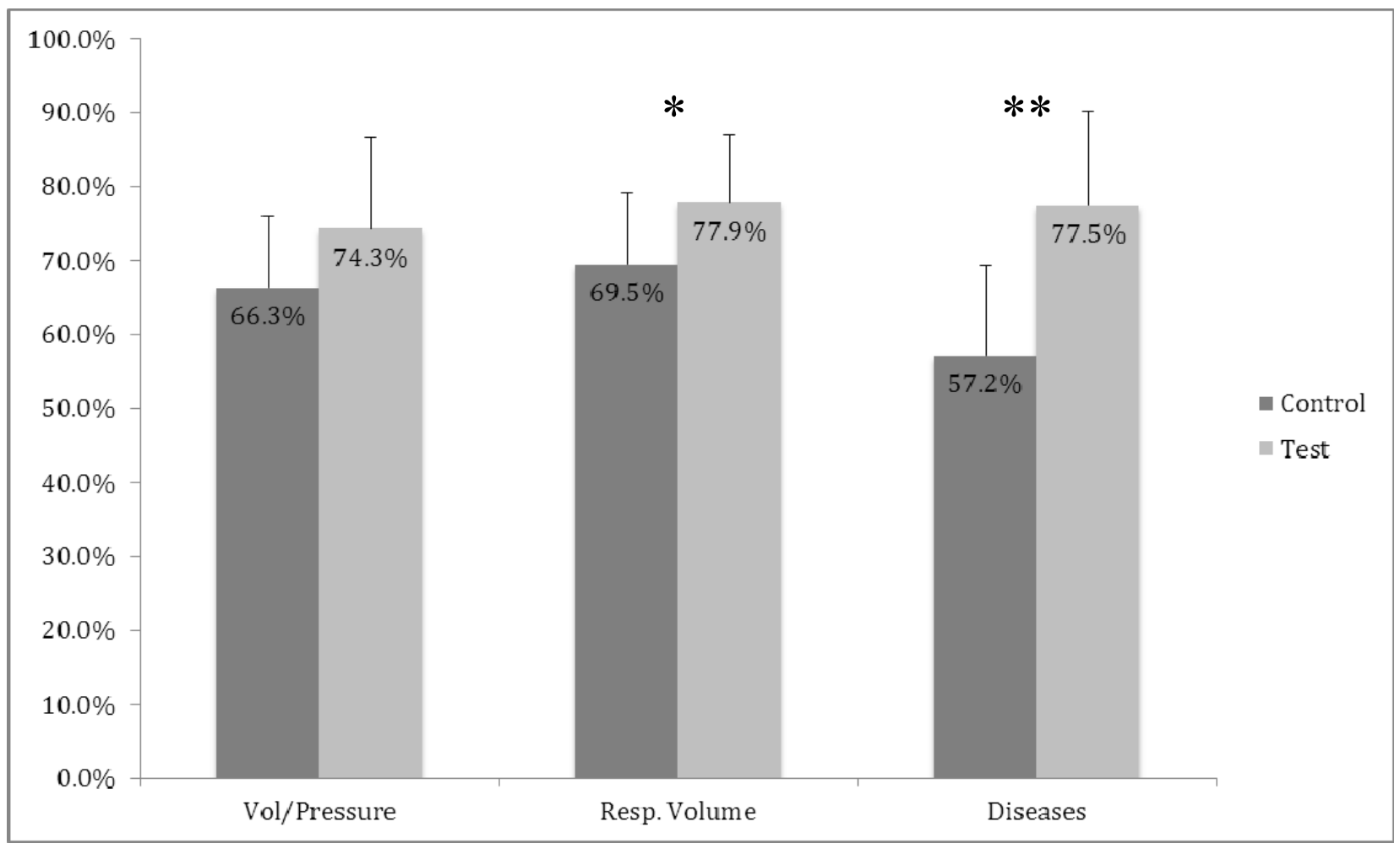

Figure 1. Comparison of Student Performance on Spirometry Concepts on Midterm Exam

The difference was statistically significant for questions relating to respiratory volume $(*, p<0.05)$ and respiratory diseases $(* *, p<0.005)$ but not for the relationship between volume and pressure $(\mathrm{p}=0.09)$

\subsection{Performance within Test Sections on Spirometry Concepts vs. Other Concepts}

We next analyzed the performance within the test sections on spirometry concepts compared to the rest of the concepts assessed on the mid-term exam (Figure 2). In each of the four semesters students performed slightly better on the spirometry concepts than on the concepts from the rest of the first 5 labs. When data of all four semesters are combined, students performed better on the spirometry concepts than on other concepts assessed on the midterm. $(76.5 \pm 4.3 \%$ vs. $70.9 \pm 1.5 \%, \mathrm{p}<0.05)$ 


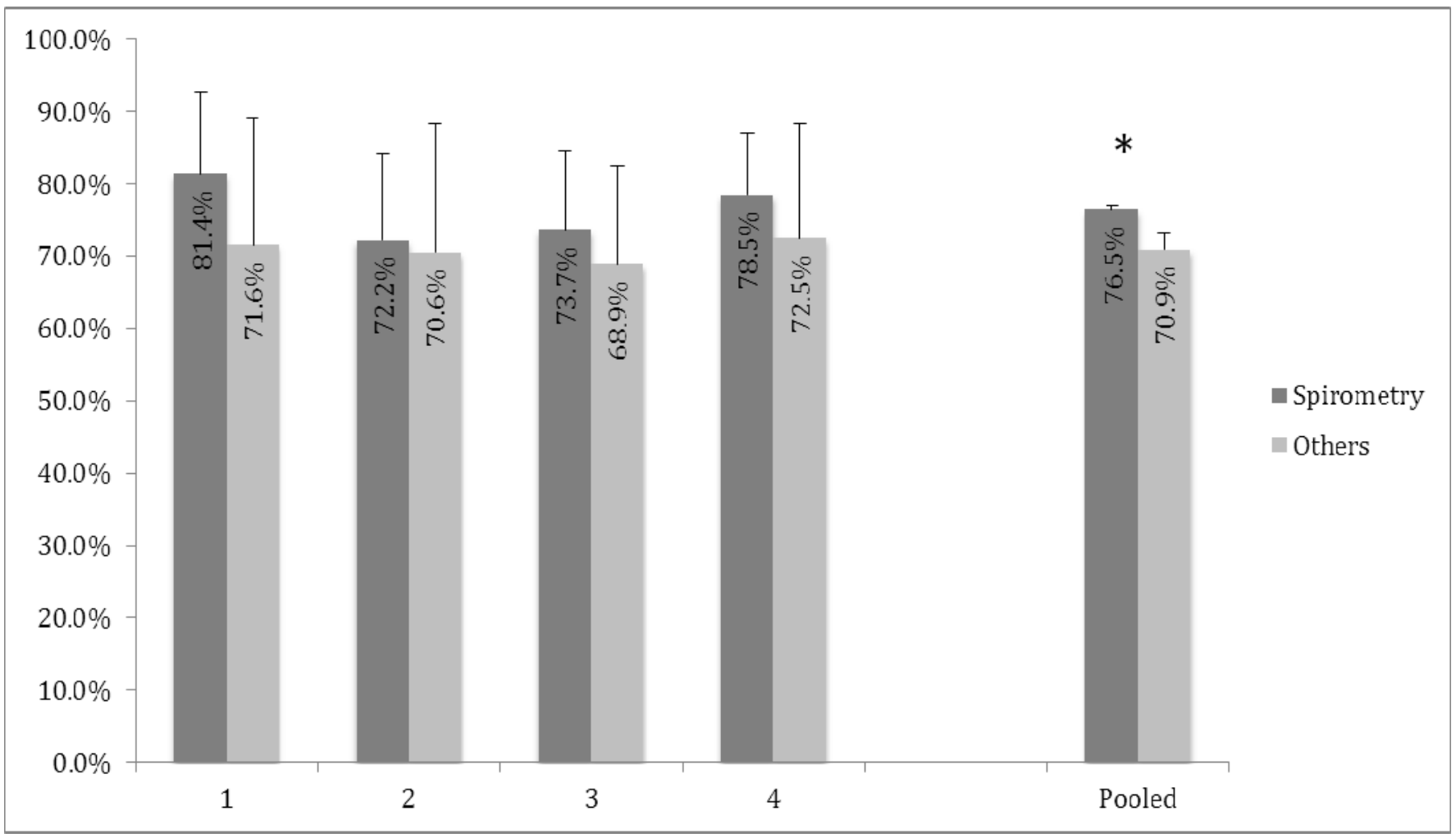

Figure 2. Comparison of student performance in test sections on spirometry concepts compared to all other concepts assessed on the midterm exam. In each section, students performed slightly better on spirometry concepts, though not significantly different ( $\mathrm{p}$ values: Section $1=0.09,2=0.78,3=0.33,4=0.15$ ). When the data for all sections are pooled, a significant difference is seen between the concepts $(*, p<0.05)$.

\subsection{Student Perceptions}

Students who participated in test sections were asked about their experience in post-lab surveys. They were told that the labs they completed were part of a curricular redesign and that an attempt was being made to determine whether the redesign was beneficial or not. Students were informed that the surveys were completely anonymous and that participation was voluntary and would in no way impact their grade. A total of 68 students $(90.6 \%)$ responded to the survey. Students were asked to rate their experience in four general categories: 1) The effect of the modifications on their understanding of content, 2) the impact on classroom experience 3) their interest in the subject matter and 4) their perception of the technology as a teaching tool.

When asked about whether the lab modifications improved understanding of respiratory physiology concepts (Table 4), more than $75 \%$ responded favorably (either Strongly Agree or Agree) for all of the concept groups, except for obstructive vs. restrictive diseases (69.2\%) and the effect of obstructive diseases on pulmonary function (69.1\%). Likewise, responses were generally favorable (more than 75\% responding Strongly Agree or Agree) for questions regarding the laboratory experience (e.g., working in groups, interacting with the data acquisition system and computer, etc.). $60.3 \%$ responded that the exercises increased their interest in respiratory physiology. Finally, on a summative evaluation, whether students preferred labs that use the technology versus those that do not, $76.5 \%$ responded favorably. 
Table 4. Student Perception of Impact of Curriculum Modification on Understanding of Key Respiratory Physiology Concepts

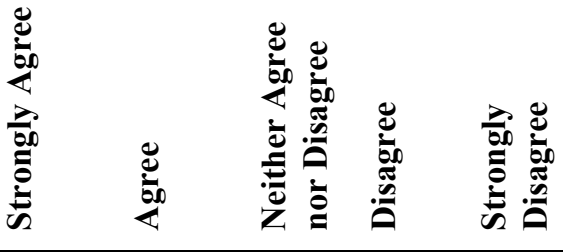

The exercise(s) we did in lab improved my understanding of...

$\begin{array}{llllll}\text { the relationship between volume and pressure in the lung. } & 32.4 \% & 55.9 \% & 5.9 \% & 4.4 \% & 1.5 \% \\ \text { the relationship between relative pressure and the flow of air into or out } & 29.4 & 51.5 & 16.2 & 1.5 & 1.5 \\ \text { of the lung } & 29.4 & 47.1 & 17.6 & 2.9 & 1.5 \\ \text { respiratory volumes } & 17.6 & 61.8 & 14.7 & 2.9 & 1.5 \\ \text { pulmonary function } & 11.8 & 57.4 & 22.1 & 7.4 & 1.5 \\ \text { obstructive vs. restrictive respiratory diseases } & 19.1 & 50.0 & 20.6 & 5.9 & 1.5 \\ \text { the effect of obstructive respiratory diseases on pulmonary function } & & \end{array}$

The exercise(s) we did in lab, improved my ability to...

\begin{tabular}{|c|c|c|c|c|c|}
\hline work & 36.8 & 52.9 & 5.9 & 1.5 & 1.5 \\
\hline interpret a graph of a live recording of a physiological variable & 26.5 & 51.5 & 10.3 & 5.9 & 1.5 \\
\hline $\begin{array}{l}\text { use a data acquisition equipment similar to the ones used in a clinical } \\
\text { setting/use computer based material }\end{array}$ & 20.6 & 58.8 & 13.2 & 5.9 & 1.5 \\
\hline $\begin{array}{l}\text { follow directions on the screen of a computer (or handout) to perform a } \\
\text { procedure/doing hands on activities }\end{array}$ & 30.9 & 50.0 & 11.8 & 1.5 & 5 \\
\hline $\begin{array}{l}\text { exercises we did increased my interest in spirometry and respiratory } \\
\text { ology }\end{array}$ & 14.7 & 45.6 & 27.9 & 8.8 & 1.5 \\
\hline nore confident working with technold & 27.9 & 51.5 & 11.8 & 5.9 & 1.5 \\
\hline all, I prefer labs & 25.0 & 51.5 & 17.6 & 4.4 & 1.5 \\
\hline
\end{tabular}

\section{Discussion}

Student perceptions of learning show significant positive response to the incorporation of active learning exercises (Berk et al., 2014; C. J. Miller \& Metz, 2014; Wilke, 2003). Our data support this view, as more than 75\% of students declared a preference for labs that incorporate the data acquisition systems. Although the survey was not mandatory, we had a high completion rate $(90.6 \%)$ indicating that students were eager to share their opinions about the modified labs. Over $60 \%$ of the students indeed specifically stated that the lab increased their interest in the topic

This student interest likely translated to better performances on the midterm exam, though this did not reach the level of significance. This is not surprising because the respiratory physiology lab was only one of six labs that were covered on the exam. In essence, our results showing test sections only slightly outperformed control sections is therefore unsurprising because of the cumulative nature of the exam. Unless the impact of the modification resulted in an overwhelming increase in student performance, we expected that the other aspects of the exam, constituting approximately $80 \%$ of the questions, would obscure any change. The comparable performance instead suggests that the two populations were not academically significantly different, removing a potential confounder for the differences that were observed. We consider it likely that the increased performance would have been statistically significant had we incorporated this approach in all or most of the 6 labs covered in the test.

When we focused on the respiratory physiology lab, we saw evidence that our modifications had an impact, as the test sections displayed a statistically significant increase in student performance on two of the three measured concepts. Approximately $78 \%$ of students in the test sections correctly answered questions related to respiratory volumes and diseases, representing about $8 \%$ and $20 \%$ performance increase on these two concepts respectively. This improved performance may be partly explained by increased student (and faculty) enthusiasm over the 
introduction of the new curriculum. As students actively acquired data, a number of them expressed verbally that they could relate the concept under study with what they observed on the computer screen. Specifically, when studying restrictive and obstructive diseases, students could very clearly see the difference in the measurements $\left(\mathrm{FEV}_{1}\right.$ for obstructive diseases and vital capacity for restrictive diseases) before and after the simulation. This stimulated the curiosity of many students and led to discussion on known diseases like asthma and tuberculosis. The apparent and immediate changes in the values that students produced may explain why this last type of question showed the largest difference between control and test sections. Likewise, the immediate readout of changes in respiratory volume (for example during forced inspiration, forced expiration or tidal breathing) may have led to increased comprehension of the concept. Finally, although test sections also performed better than control sections on the questions related to the relationship between volume, pressure and airflow, the difference was not statistically significant. Unlike the other two concept groups, understanding these relationships requires more abstract thought and comprehension of advanced concepts in fluid dynamics (e.g., Boyle's Law). Our modification, while demonstrating the physical changes, is perhaps incomplete in that there is not a review of fluid dynamics before the breathing experiment is done. It is also worth noting that among the concepts in respiratory physiology, the relationship between alveolar pressure and volume has proven to be among the most challenging for undergraduates (J. A. Michael et al., 1999).

Interestingly, there was a poor correlation between student opinions on their understanding of concepts and their subsequent performance on the tests. On one hand, students thought they understood the relation between volume and pressure very well (88.3\% favorable response), but had the lowest performance on this concept. On the other hand, they weren't as confident with their perceptions of pulmonary disease understanding ( $69.1 \%$ favorable response) but had the highest performance on this concept. The latter result is consistent with the finding that community college students often struggle with confidence issues and often underestimate their own abilities (Hinds, 1999; McKee, 2002). While this does not explain the former result, overall, our data reflect the commonly observed disagreement between perception and performance (Goodwin, Miller, \& Cheetham, 1991; Lake, 2001).

We hypothesize that our observed inconsistencies between performance and perception may be partially due to the specific concepts that we measured. Students usually had no problem memorizing the relationship between alveolar volume and pressure ("As volume increases, pressure decreases; as volume decreases, pressure increases."), which represents a shallow form of learning. Consequently, they had a high opinion of their understanding of this relationship, simply because they were able to repeat it. However, when confronted with an exam question that required a deeper understanding (as shown in Table 3), applying this relationship rather than just repeating what they had memorized, it became evident that they had overestimated their understanding. Our data showing that our active learning lab improved student performance on this concept, though not to the level of statistical significance, supports this view while also suggesting that a hands-on approach to this concept can be helpful. Redesigning the lab to incorporate discussion of Boyle's Law or simply spending more time on this critical concept could result in a significant improvement.

Conversely, understanding pulmonary disease required a synthesis of many concepts (e.g., resistance, air flow, forced expiratory volume in one second, vital capacity and respiratory anatomy). Students may have perceived that they could not integrate these concepts into a complete picture of pulmonary disease and thus rated their understanding poorly. However, our exam questions focused on one concept, specifically the change in respiratory measurement that they directly observed and noticed significant changes during the simulation. While we feel that there is not a significant difference in the difficulty level of the questions from across the concept groups - we categorized them all as Comprehension or Application questions according to Bloom's taxonomy (Bloom \& Krathwohl, 1956) - it is possible that some difference in the questions themselves is at least partly responsible for the observed differences. However, we theorize that the physical act of performing the experiment and noticing this difference may have a significant impact on their understanding, rather than just talking about this concept in theory.

It is worth noting that students rated their interactions with fellow students favorably. The effect of this apparent interest in collaborative learning on their test performance cannot be discounted, especially for students who intend to enter the Allied Health fields. These are highly collaborative endeavors and often require extensive communications between multiple professionals. Our lab represents a simplistic reenactment of the types of groups that our students may find themselves in during their professional lives.

Students also rated the use of technology highly, another important skill that is increasingly in demand as allied health fields are becoming more reliant on clinical technology. While students are clearly adept at the use of personal technology, the use of clinical or medical technology is different. (Our personal observation is that students are 
initially hesitant with the apparatus and become more comfortable during the lab period.) Introducing students to technology, even if it does not exactly replicate the type of equipment that they will see in occupational settings, is beneficial. In our study, more than $80 \%$ of students reported greater confidence working with technology as a result of the modified lab. We can reasonably expect this to be advantageous for these students as they encounter technology in the clinical setting.

Overall, we conclude that the introduction of a spirometry lab incorporating active learning strategies in a community college setting was successful, both in terms of student performance and perceptions. Students performed significantly better in two (respiratory volumes and obstructive/restrictive diseases) of the three respiratory physiology concepts tested than control sections exposed to a more traditional, lecture-based approach. We also found that students had positive experiences in the use of technology, collaborative learning, interest in spirometry and respiratory physiology concepts, ability to follow directions among others. We speculate that this increased enthusiasm, in addition to the live data acquisition, may have played a role in better test performances.

Based on these data and others in the literature we expect that incorporating the concepts of active learning into the entire laboratory curriculum across both semesters will improve learning outcomes for our Allied Health students. We will begin the revision of additional labs in our department to incorporate similar active learning strategies in the curriculum.

\section{References}

Abraham, R. R., Ramnarayan, K., George, B. M., Adiga, I., Kumari, G. R., Suvarna, N., . . Jamil, W. (2012). Effects of problem-based learning along with other active learning strategies on short-term learning outcomes of students in an Indian medical school. International Journal of Health \& Allied Sciences, 1(2), 98. http://dx.doi.org/10.4103/2278-344X.101703

Beeson, S. A., \& Kissling, G. (2001). Predicting success for baccalaureate graduates on the NCLEX-RN. J Prof Nurs, 17(3), 121-127. http://dx.doi.org/10.1053/jpnu.2001.23382

Berk, L. J., Muret-Wagstaff, S. L., Goyal, R., Joyal, J. A., Gordon, J. A., Faux, R., \& Oriol, N. E. (2014). Inspiring careers in STEM and healthcare fields through medical simulation embedded in high school science education. Advances in physiology education, 38(3), 210-215. http://dx.doi.org/10.1152/advan.00143.2013

Bligh, D. A. (1998). What's the Use of Lectures? : Intellect books.

Bloom, B. S., \& Krathwohl, D. R. (1956). Taxonomy of educational objectives: The classification of educational goals. Handbook I: Cognitive domain.

Bonwell, C. C., \& Eison, J. A. (1991). Active Learning: Creating Excitement in the Classroom. 1991 ASHE-ERIC Higher Education Reports: ERIC.

Bransford, J. D., Brown, A. L., \& Cocking, R. R. (2000). How people learn: National Academy Press Washington, DC.

Brasell, H. (1987). The effect of real - time laboratory graphing on learning graphic representations of distance and velocity. Journal of research in science teaching, 24(4), 385-395. http://dx.doi.org/10.1002/tea.3660240409

Brown, P. J. (2010). Process-oriented guided-inquiry learning in an introductory anatomy and physiology course with a diverse student population. Advances in physiology education, 34(3), 150-155. http://dx.doi.org/10.1152/advan.00055.2010

Casotti, G., Rieser-Danner, L., \& Knabb, M. T. (2008). Successful implementation of inquiry-based physiology laboratories in undergraduate major and nonmajor courses. Advances in physiology education, 32(4), 286-296. http://dx.doi.org/10.1152/advan.00100.2007

Chaplin, S. B. (2003). Guided development of independent inquiry in an anatomy/physiology laboratory. Advances in physiology education, 27(1-4), 230-240. http://dx.doi.org/10.1152/advan.00002.2003

Dantas, A. M., \& Kemm, R. E. (2008). A blended approach to active learning in a physiology laboratory-based subject facilitated by an e-learning component. Advances in physiology education, 32(1), 65-75. http://dx.doi.org/10.1152/advan.00006.2007

Dewey, J., \& Dewey, E. (1915). Schools of to-morrow: Dent.

DiPasquale, D. M., Mason, C. L., \& Kolkhorst, F. W. (2003). Exercise in Inquiry: Critical Thinking in an 
Inquiry-Based Exercise Physiology Laboratory Course. Journal of College Science Teaching, 32(6), 388-393.

Freeman, S., Eddy, S. L., McDonough, M., Smith, M. K., Okoroafor, N., Jordt, H., \& Wenderoth, M. P. (2014). Active learning increases student performance in science, engineering, and mathematics. Proceedings of the National Academy of Sciences, 201319030. http://dx.doi.org/10.1073/pnas.1319030111

Gilmore, M. (2008). Predictors of success in associate degree nursing programs. Teaching and Learning in Nursing, 3(4), 121-124. http://dx.doi.org/10.1016/j.teln.2008.04.004

Goodwin, L., Miller, J. E., \& Cheetham, R. D. (1991). Teaching freshmen to think: does active learning work? BioScience, 719-722.

Grossbach, A., \& Kuncel, N. R. (2011). The predictive validity of nursing admission measures for performance on the national council licensure examination: A meta-analysis. Journal of Professional Nursing, 27(2), 124-128. http://dx.doi.org/10.1016/j.profnurs.2010.09.010

Halonen, J. S., Brown-Anderson, F., \& McKeachie, W. J. (2002). Teaching thinking. McKeachie's teaching tips: Strategies, research, and theory for college and university teachers, 284-290.

Harrison, J. F., Nichols, J. S., \& Whitmer, A. C. (2001). Evaluating the impact of physical renovation, computerization, and use of an inquiry approach in an undergraduate, allied health human anatomy and physiology lab. Advances in physiology education, 25(4), 202-210.

Hinds, I. (1999). Special needs of adult learners in science (Biology). Community Review, 17, $42-48$.

Klein, J., \& Doran, M. (1999). Implementing individual and small group learning structures with a computer simulation. Educational Technology Research and Development, 47(1), 97-109. http://dx.doi.org/10.1007/BF02299479

Lake, D. A. (2001). Student performance and perceptions of a lecture-based course compared with the same course utilizing group discussion. Physical Therapy, 81(3), 896-902.

McKeachie, W., \& Svinicki, M. (2005). How to make lectures more effective. Teaching tips: Strategies, research, and theory for college and university teachers, 11, 52-68.

McKee, G. (2002). Why is biological science difficult for first-year nursing students? Nurse education today, 22(3), 251-257. http://dx.doi.org/10.1054/nedt.2001.0700

McLaughlin, J. E., Roth, M. T., Glatt, D. M., Gharkholonarehe, N., Davidson, C. A., Griffin, L. M., . . Mumper, R. J. (2014). The Flipped Classroom: A Course Redesign to Foster Learning and Engagement in a Health Professions School. Academic Medicine, 89(2), 236-243 210.1097/ACM.0000000000000086. http://dx.doi.org/10.1097/ACM.0000000000000086

McManus, E. S., \& Sieler, P. A. (1998). Freedom to enjoy learning in the 21st century: developing an active learning culture in nursing. Nurse education today, 18(4), 322-328. http://dx.doi.org/10.1016/S0260-6917(98)80050-6

Michael, J. (2006). Where's the evidence that active learning works? Advances in physiology education, 30(4), 159-167. http://dx.doi.org/10.1152/advan.00053.2006

Michael, J. A., Richardson, D., Rovick, A., Modell, H., Bruce, D., Horwitz, B., . . . Williams, S. (1999). Undergraduate students' misconceptions about respiratory physiology. Advances in physiology education, 22, 127-135.

Miller, C. J., \& Metz, M. J. (2014). A comparison of professional-level faculty and student perceptions of active learning: its current use, effectiveness, and barriers. Advances in physiology education, 38(3), 246-252. http://dx.doi.org/10.1152/advn.00014.2014

Miller, S. A., Perrotti, W., Silverthorn, D. U., Dalley, A. F., \& Rarey, K. E. (2002). From college to clinic: reasoning over memorization is key for understanding anatomy. The Anatomical Record, 269(2), 69-80. http://dx.doi.org/10.1002/ar.10071

Newton, S. E., Smith, L. H., Moore, G., \& Magnan, M. (2007). Predicting early academic achievement in a baccalaureate nursing program. Journal of Professional Nursing, 23(3), 144-149. http://dx.doi.org/10.1016/j.profnurs.2006.07.001

Nieder, G. L., Parmelee, D. X., Stolfi, A., \& Hudes, P. D. (2005). Team - based learning in a medical gross anatomy and embryology course. Clinical Anatomy, 18(1), 56-63. http://dx.doi.org/10.1002/ca.20040 
Quick, M. M., Krupa, K. C., \& Whitley, T. W. (1985). Using admission data to predict success on the NCLEX-RN in a baccalaureate program. Journal of Professional Nursing, 1(6), 364-368. http://dx.doi.org/10.1016/S8755-7223(85)80060-0

Rathner, J. A., Hughes, D. L., \& Schuijers, J. A. (2013). Redesigning A Core First Year Physiology Subject In Allied Health To Achieve Better Learning Outcomes. International Journal of Innovation in Science and Mathematics Education (formerly CAL-laborate International), 21(2).

Rodenbaugh, D. W., Lujan, H. L., \& DiCarlo, S. E. (2012). Learning by doing: construction and manipulation of a skeletal muscle model during lecture. Advances in physiology education, 36(4), 302-306. http://dx.doi.org/10.1152/advan.00093.2012

Sciutto, M. J. (1995). Student-centered methods for decreasing anxiety and increasing interest level in undergraduate statistics courses. Journal of Instructional Psychology.

Seldomridge, L. A., \& DiBartolo, M. C. (2004). Can success and failure be predicted for baccalaureate graduates on the computerized NCLEX-RN? Journal of Professional Nursing, 20(6), 361-368. http://dx.doi.org/10.1016/j.profnurs.2004.08.005

Seymour, E., Wiese, D. J., Hunter, A., \& Daffinrud, S. M. (2000). Creating a better mousetrap: On-line student assessment of their learning gains. Paper presented at the National Meeting of the American Chemical Society.

Simon, E. B., McGinniss, S. P., \& Krauss, B. J. (2013). Predictor variables for NCLEX-RN readiness exam performance. Nursing education perspectives, 34(1), 18-24. http://dx.doi.org/10.5480/1536-5026-34.1.18

Somers, K., Dilendik, J., \& Smolansky, B. (1996). Class Activities with Student-Generated Data. The Mathematics Teacher, 105-107.

Stork, D. (2003). Teaching statistics with student survey data: A pedagogical innovation in support of student learning. Journal of Education for Business, 78(6), 335-339. http://dx.doi.org/10.1080/08832320309598623

Vasan, N. S., DeFouw, D. O., \& Holland, B. K. (2008). Modified use of team - based learning for effective delivery of medical gross anatomy and embryology. Anatomical sciences education, 1(1), 3-9. http://dx.doi.org/10.1002/ase.5

Wilke, R. R. (2003). The effect of active learning on student characteristics in a human physiology course for nonmajors. Advances in physiology education, 27(4), 207-223. http://dx.doi.org/10.1152/advan.00003.2002

Yates, L., \& Sandiford, J. (2013). Community college nursing student success on professional qualifying examinations from admission to licensure. Community College Journal of Research and Practice, 37(4), 319-332. http://dx.doi.org/10.1080/10668920903530013

Yeom, Y.-J. (2013). An investigation of predictors of NCLEX-RN outcomes among nursing content standardized tests. Nurse education today, 33(12), 1523-1528. http://dx.doi.org/10.1016/j.nedt.2013.04.004

Yoder, J. D., \& Hochevar, C. M. (2005). Encouraging active learning can improve students' performance on examinations. Teaching of Psychology, 32(2), 91-95. http://dx.doi.org/10.1207/s15328023top3202_2

Zimmermann, M., \& Eckert, G. P. (2010). Enhanced student experience: an analysis of subjective evaluation and objective learning success after the transformation of a pharmaceutical physiology course. Advances in physiology education, 34(1), 1-10. http://dx.doi.org/10.1152/advan.00091.2009 